\title{
Spectrum of dermatological manifestation in all female attending tertiary health care in a developing country
}

\author{
Sharma P. ${ }^{1}$, Shah A. ${ }^{2}$, Lachhiramani $\mathbf{R}^{3}$, Jagati $A^{4}$ \\ ${ }^{1}$ Dr. Parikshit Sharma, ${ }^{2}$ Dr. Akhil Shah, ${ }^{3}$ Dr. Radha Lachhiramani, above authors are attached with Department of \\ Dermatology, Index Medical College and Research Center, Indore, Madhya Pradesh, ${ }^{4}$ Dr. Ashish Jagati, Department of \\ Dermatology, Smt. NHL Municipal Medical College, V. S. Hospital, Ellis Bridge, Ahmedabad, Gujrat, India.
}

Corresponding Author: Dr. Ashish Jagati, Room No.9; Skin OPD, VS Hospital, Ellis Bridge, Paldi Road, Ahmedabad, Gujarat, India, Email: jagatiashish@gmail.com

\begin{abstract}
Background: Skin diseases occur all over the world at significant levels. Skin conditions are both wide spread and among the most prevalent and disabling diseases, and a source of considerable loss of healthy life. They have been identified as a public health problem in developing countries. Skin diseases affect all segments of the population without ethnic variability but are more prevalent among children and women in low socioeconomic groups, essentially due to poor hygienic practices. Objective: Objective was to study the dermatoses in females attending a tertiary health care dermatology clinic. Patients and Methods: Total 600 female patients who were attending the Skin outpatient department during data collection period and were willing to participate constituted the study population. The diseases of the patients were then classified according to infectious and non-infectious dermatoses. Results: Out of 600 Female patients, $36 \%$ belonged to the age group of $21-30$ years, $28 \%$ were illiterate and $59 \%$ were unskilled worker. $58 \%$ of the patients had various noninfectious dermatoses while $42 \%$ had various infectious dermatoses. Conclusions: Apart from environmental factors, skin diseases are mostly dependent on occupation, socioeconomic status and age of the patients.
\end{abstract}

Key word- Dermatoses, Female, Infectious, Inflammatory, Autoimmune disorder

\section{Introduction}

Dermatological conditions are a common cause of morbidity in both rural and urban areas of developing countries[1]. These account for a high proportion of visits to healthcare facilities. The pattern of dermatoses in a particular area is determined by many factors, such as geographical location including environmental and climatic factors, socio-economic status, literacy levels, and psychological, cultural and racial factors [2,3].

In developing country women are sidelined due to social stigma (in conditions like vitiligo, leprosy), or embarrassment (in cases of venereal diseases like syphilis, candidiasis, herpes). Moreover, women also tend to have nutritional deficiencies (pellagra, scurvy), and other maladies due to age-old practices and superstitions, especially in the rural community. Further more, some conditions like psoriasis and atopic dermatitis are worsened in rural womenfolk due to, irregular follow-ups and recurrence of these conditions.

Manuscript received: $25^{\text {th }}$ November 2018

Reviewed: $4^{\text {th }}$ Dcember 2018

Author Corrected: $10^{\text {th }}$ December 2018

Accepted for Publication: $14^{\text {th }}$ December 2018

\section{Aims and Objective}

Objective was to study the dermatoses in females attending a tertiary health care dermatology clinic.

\section{Material and Methods}

Place of study- Index medical college, Indore a tertiary care center of central India

Study type- Cross sectional observational study.

Study Duration- 18 months (June 2016 to December 2017)

Sample Method- Simple random sampling

\section{Inclusion criteria}

1. All the female patients attended dermatology outpatient department.

\section{Treatment Naïve patient}

Exclusion criteria- Patients who were not willing to give consent 


\section{Original Research Article}

Study was conducted after the Institutional Ethics Committee clearance. This study was in accordance with Declaration of Helsinki.

Total 600 femalepatients were enrolled in the study. In case of patients aged $\leq 12$ years accompanying guardians were interviewed. Dermatological diagnosis made by dermatologists was recorded. In cases of suspicion, appropriate diagnostic tests (biopsy, Tzanck smear, scraping for fungus, etc.) were performed to come to a conclusion. The patient information included socio-demographic factors like age, sex, residence, religion, socio-economic factors and personal characteristics like habits, hygiene.The diseases of the patients were then classified according to infectious and non-infectious dermatoses.

\section{Results}

Total 600 patients were included in our study.Highest number of females belonged to the age group of 21-30 years $36 \%$ $(n=216)$ and 31-40 years 23\% $(n=138)$ (Table 1). Most of the patients in our study population were either illiterate (Never been to school) $28 \%(n=168)$ or educated up to primary school $23.5 \%(n=141)$ (Table 2$)$.

Our study population had highest number of unskilled workers 59\% $(n=354)$ followed by a sizeable number of students19\% $(n=114)$ thereby giving a wide spectrum of diseases; (Table 3).12\% $(n=72)$ of females in our study suffered from Diabetes Mellitus while 51 (8.5\%) of females suffered from Hypertension while one patient suffers from diabetes and hypertension both.

Table-1: Demographic Distribution of Patients.

\begin{tabular}{|c|c|c|}
\hline Groups: & No. of Patients $(\mathbf{n}=\mathbf{6 0 0}):$ & \% of Patients: \\
\hline $1-10$ years & 72 & $12 \%$ \\
\hline $11-20$ years & 66 & $11 \%$ \\
\hline $21-30$ years & 216 & $36 \%$ \\
\hline $31-40$ years & 138 & $23 \%$ \\
\hline $41-50$ years & 66 & $11 \%$ \\
\hline $51-60$ years & 24 & $4 \%$ \\
\hline$>60$ years & 18 & $3 \%$ \\
\hline
\end{tabular}

Table-2: Literacy rate of the study population

\begin{tabular}{|c|c|c|}
\hline Groups: & No. of Patients $(\mathbf{n = 6 0 0}):$ & \% of Patients: \\
\hline Illiterate (never been to school) & 168 & $28 \%$ \\
\hline Primary & 141 & $23.5 \%$ \\
\hline Higher Secondary & 117 & $19.5 \%$ \\
\hline Secondary & 105 & $17.5 \%$ \\
\hline Graduate & 69 & $11.5 \%$ \\
\hline
\end{tabular}

Table-3: Occupation/Employment Status of Patients

\begin{tabular}{|c|c|c|}
\hline Groups: & No. of Patients $(\mathbf{n = 6 0 0}):$ & \% of Patients: \\
\hline Unskilled Worker & 354 & $59 \%$ \\
\hline Student & 114 & $19 \%$ \\
\hline Homemaker & 54 & $9 \%$ \\
\hline Skilled Worker & 30 & $5 \%$ \\
\hline Professional & 30 & $5 \%$ \\
\hline Service & 18 & $3 \%$ \\
\hline
\end{tabular}


Table-4: Distribution of Patients with Non-Infectious Dermatoses.

\begin{tabular}{|c|l|c|c|}
\hline Sr. No.: & Non-Infectious Dermatoses: & No. of Patients: $(\mathbf{n}=348)$ & \% of Patients: \\
\hline 1 & Acne & 84 & $14 \%$ \\
\hline 2 & Eczema & 64 & $10.67 \%$ \\
\hline 3 & Papulo-squamous Disorders & 38 & $6.33 \%$ \\
\hline 4 & Benign Tumours & 36 & $6 \%$ \\
\hline 5 & Pigment Disorders & 22 & $3.67 \%$ \\
\hline 6 & Hair Disorders & 14 & $2.33 \%$ \\
\hline 7 & Insect Bite & 12 & $2 \%$ \\
\hline 8 & Metabolic Disorders & 10 & $1.67 \%$ \\
\hline 9 & Immuno-bullous Disorders & 8 & $1.33 \%$ \\
\hline 10 & Urticaria & 8 & $1.33 \%$ \\
\hline 11 & Connective Tissue Disorders & 6 & $1 \%$ \\
\hline 12 & Photodermatoses & 6 & $1 \%$ \\
\hline 13 & Keratinization Disorders & 6 & $1 \%$ \\
\hline 14 & Nevus & 4 & $0.67 \%$ \\
\hline 15 & Vasculitis & 30 & $5 \%$ \\
\hline
\end{tabular}

The various dermatoses in our study had been divided into 2 sub-headings- Infectious dermatoses \& Non-Infectious dermatoses. Out of 348, most common Non-Infectious dermatoses found in our study were acne (14\%), eczema (10.67\%) \& papulosquamous disorders $(6.33 \%)$ (Figure 1) followed by benign tumors $(6 \%)$, pigment disorder $(5 \%)$, hair disorder $(3.67 \%)$, insect bite reactions $(2.33 \%)$, metabolic disorder $(2 \%)$, immunobullous disorder( $1.67 \%)$, urticaria $(1.33 \%)$, connective tissue disorder (1.33\%), photodermatosis (1\%), Keratinization disorder(1\%) (Figure 2), Nevus (1\%) (Figure 3 ) and vasculitis $(0.67 \%)$ (Table 4$)$.

Table-5: Distribution of Patients with Infectious Dermatoses.

\begin{tabular}{|c|c|c|c|}
\hline Sr. No.: & Infectious Dermatoses: & No. of Patients (n=252): & \% of Patients: \\
\hline 1 & Fungal & 120 & $20 \%$ \\
\hline 2 & Scabies & 48 & $8 \%$ \\
\hline 3 & Bacterial & 28 & $4.67 \%$ \\
\hline 8 & Leprosy & 24 & $4 \%$ \\
\hline 4 & Viral & 18 & $3 \%$ \\
\hline 7 & STIs & 12 & $2 \%$ \\
\hline 6 & Onychomycosis & 4 & $0.67 \%$ \\
\hline 5 & Intertrigo & 3 & $0.5 \%$ \\
\hline 9 & Others & 0 & $0 \%$ \\
\hline
\end{tabular}

Among Infectious dermatoses $(n=252)$, Fungal Infection $20 \%(n=120)$ was the most common infectious dermatological condition followed by Scabies $8 \%(n=48)$. All bacterial skin infectionscombined together, except leprosy, were the 3rd most common infectious skin condition in $4.67 \%(n=28)$ found to be prevalent in our study population. $4 \%(n=24)$ of the patient had leprosy. All other conditions had a very low prevalence rate of $\leq 2 \%$ (Table 5 )

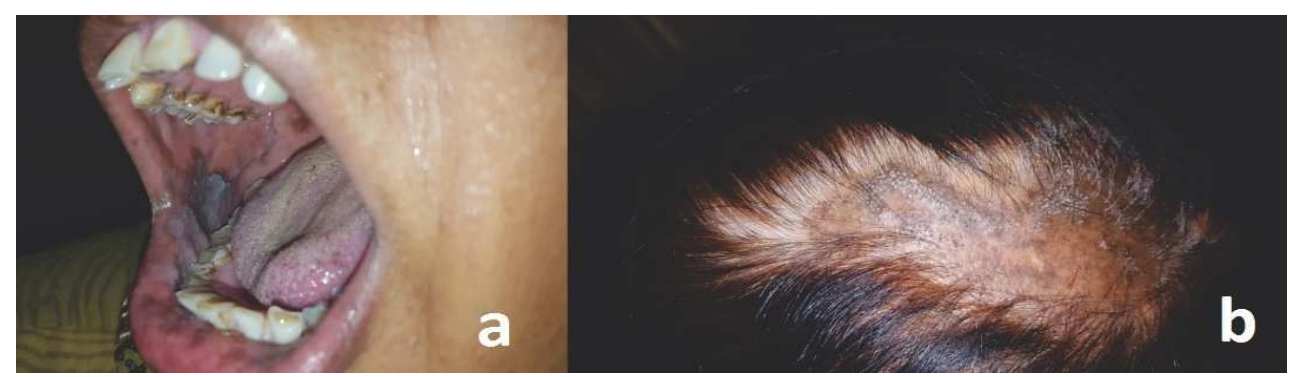

Figure-1: Lichen-Planus-a) Oral Lichen Planus b) Lichen-Planopilaris 


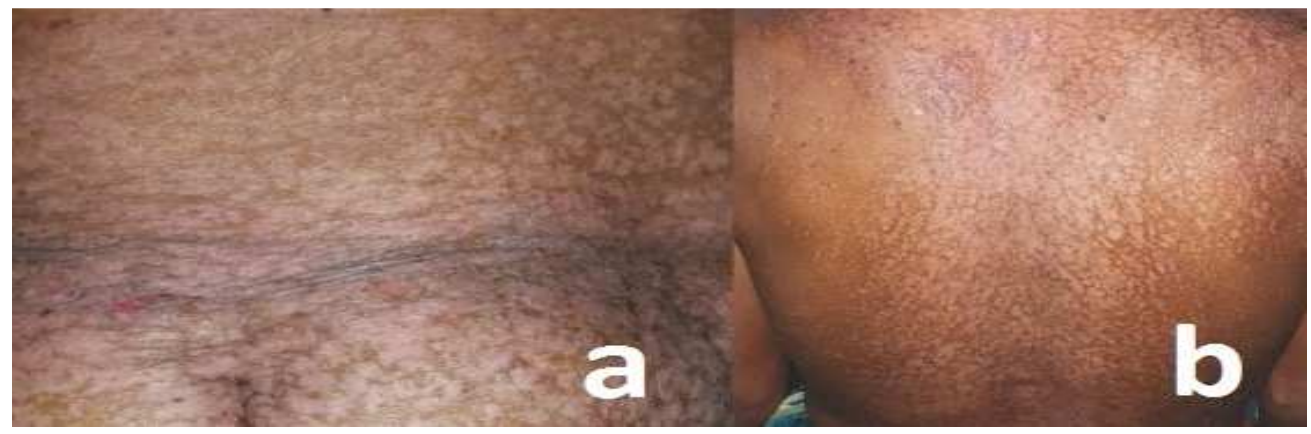

Figure-2: Darier disease a) abdomen b)back

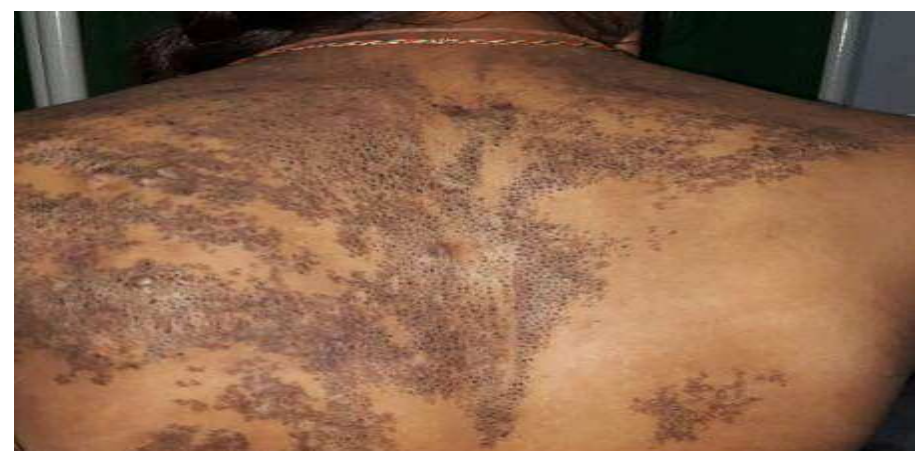

Figure-3: Bilateral-Nevus- Comedonicus

\section{Discussion}

Types of skin diseases vary from country to country. Even within the same country there is considerable regional variation. The pattern of dermatoses in a given area is influenced by various factors, such as the local climatic and socio-economic conditions in addition to literacy, psychosocial and cultural environment and racial origin. Due to lack of resources in rural areas, skin diseases are typically neglected at the primary healthcare setup [4-11]. Thus the impact of skin diseases must be viewed from a broader healthcare perspective, because regional variations in disease databases may reflect differences not only in prevalence but also availability of qualified dermatology services.

Proportion of children, adolescents and teenagers formed approximately one-fifth $(20.5 \%)$ of the studied population. Most of the patients (82\%) were under 40 years of age. Similar bio demographic findings were reported by Emmanouil $\mathrm{K} \mathrm{S}$ et al, in their study at a Mediterranean island [12].

Almost $30 \%$ of our subjects are illiterate and nearly $60 \%$ of the population comprises of unskilled workers (especially farmers). The study by Florence Dalgard et al exhibited gender and ethnic differences in the reporting of skin complaints [13]. This interesting finding was borne out in our study too. Among the total interviewed patients, Non-infectious dermatoses $(58 \%)$ were more common than Infectious dermatoses (42\%), similar to the study in Kerala (Non-Infectious $57.07 \%$, Infectious $43.4 \%$ ) by Rao et al [7]. Within the Noninfectious dermatoses group, Acne, Eczema and Papulosquamous disorders were found to be the most common diagnoses $(31 \%)$. Likewise in the study done by Emmanouil K S and others in a Mediteranean island, Allergic dermatitis and Urticaria were the most commonly found non-infectious dermatoses (35.7\%) [12].

Contrarily in our study, due to higher number of younger patients (20-30 years), acne was the most common non-infectious dermatoses. This can further be attributed to non-availability of proper treatment and medical facilities in rural areas. Inadvertent use of over the counter creams, oils and inadequate facial hygiene may be some of the other reasons.

Consistent with our findings, the prevalence of acne vulgaris was higher in the adolescent and teenage population of a study by Sudip Das et al [14]. The prevalence of Psoriasis in our study was found to be $6.33 \%$ which is similar to that in another study at a tertiary hospital in Kerala (7.75\%)[15].

Two separate studies from North Eastern India depicted eczema rates of around 18 to $23 \%$ [5,10]. The reasons for this could be due to the land-locked nature of both these areas with consequent arid climates, leading to 


\section{Original Research Article}

higher cases of eczematous disorders. A comparatively higher proportion of allergic conditions in our populace as well as the Mediterranean one is likely due to more farmers in both these studies. Farmers are frequently exposed to hay, parthenium and various pesticides which are well-known causes of hand eczema, contact and atopic dermatitis. Additionally, due to higher exposure to sunlight, these patients also showed a greater incidence of photodermatitis.

Another specific reason for a proportionately higher number of non-infectious dermatoses is that antiinfective treatment provided by general practitioners for common infectious conditions like tinea and scabies is generally effective. On the other hand, commonly occurring non-infectious dermatoses are referred to higher centers by primary care physicians owing to difficulty in diagnosis and consequent inappropriate management leading to intractable recurrences.

Regarding the Infectious dermatoses group in our study, Fungal Infections $(23 \%)$ were the commonest form of dermatological infection, followed by Scabies (8\%). Bacterial skin infections together constituted about $5 \%$ of the cases. Proportion of Insect bites (10.2\%) in the Mediterranean study was relatively higher than in ours (only 2.33\%) [16].

This significant difference may be potentially explained by geography and the fact that our study was conducted in a tertiary care hospital. In contrast, at their local primary health center, affected individuals may have sought immediate treatment promptly owing to the painful nature of this problem.

A study in Dermatology O.P.D of Guwahati Medical college in India by Das KK found Eczema (23.1\%), Pyoderma (14.29\%), Fungal infections (14.24\%) and Psoriasis $(7.7 \%)$ were the major skin diseases in that part of our country [5].Study done by Th. Bijayanti Devi in North Eastern India also found Eczema (17.48\%), Fungal (17.19\%), Pyoderma (9.1\%) and Scabies $(8.97 \%)$ were the major pattern of skin morbidities [10]. Our study has a similar distribution of prevalence of dermatoses compared to the results of the above 2 studies conducted in the North-Eastern states of India.

Notably, fungal diseases (20.6\%) were the commonly found skin infection among children reported by Nuzhat Yasmeen in their 2005 study in Pakistan, which is similar to our study [17. In a 2009, publication from a tertiary care hospital in Kerala by N. Asokanfungal infection (18.74\%), Bacterial (6.74\%) and Parasitic (4.31\%) were commonly found among Infectious skin disorders as opposed to Eczema (21.83\%)[18]. This study showed that the causes of infectious skin diseases for which the patients paid recurrent visits, some health education should also be given along with medical treatment to reduce the disease burden. This study showed that type of skin diseases significantly varied with socio-economic classes.

Reason is that patients coming from lower socioeconomic category had low awareness, might live in overcrowded condition with poor environmental sanitation. For example, slum dwellers in our study usually presented with candidiasis, paronychia and hand eczemas.

For infectious dermatoses, by reviewing different studiesit is clear that the fungal or bacterial infections are the commonest infectious skin disorders instead of parasitic and protozoal infestations of our study $[4,5,8$, $9,11,12,14,16]$. This can be primarily ascribed to the vast rural population served by our tertiary-care institution.

In the spectrum of superficial fungal infections, tinea corporis is the most common dermatophyte in most Indian studies $[4,5,9,19]$. We have recorded a similar trend. However, pertaining to deep mycoses, there were only 2 reported cases in our study which is far less compared to above described studies $[4,12]$.

The incidence of fungal, bacterial and viral infections of many studies are very close to our study $[4,5,10]$.

Leprosy incidence of a few Indian studies show wide variations $(0.41-5.68 \%)$.We found leprosy in $1.3 \%$ of our female patients. This is similar to one study butappreciably lesser thananother $[14,20]$. In general, the incidence of leprosy has largely decreased but there is a recent surge due to inaccurate diagnosis, poor compliance and improper management in primary healthcare centers.

In the context of STI's, our study has documented a low incidence $(2 \%)$ of mainly non-bacterial STIs (genital herpes and warts). This is quite low compared to most Indian studies (2.26-5.4\%). But it lies within the range of 2 other Indian reports (0.63-2.14\%). This may be attributed to increased awareness of these conditions, easy availability of antibiotics and syndromic management of these cases at the primary healthcare level. 


\section{Original Research Article}

Infectious skin diseases were significantly more among patients suffering from uncontrolled diabetes mellitus and poor hygienic conditions, which constituted $12 \%$ of our study population (72 patients). This study showed that infectious dermatoses were characteristically higher among those who had history of contact. Some of our study findings were also supported by WHO in their report that four main factors have been generally responsible for the frequent occurrence of common skin diseases in developing areas: a low level of hygiene, differential access to water, overcrowding and climatic factor [6].

\section{Conclusion}

An important finding of our study was that apart from environmental factors, skin diseases are mostly dependent on occupation, socioeconomic status and age of the patients. The similarities and differences in the prevalence of certain infectious and non- infectious skin diseases between our study and other studies from different geographical areas highlights, that all the above-mentioned factors interplay in the causation.

Contribution- All the authors contributed equally in study design. Dr Parikshit Sharma and Dr Radha collected the data. Data was compiled by Dr Radha, Dr Akhil and Dr Ashish. Manuscript prepared by Dr Ashish and Dr Akhil. Prepared manuscript was approved by all the authors before submission.

What this study adds to existing knowledge? The study shows that infectious skin diseases significantly varied in prevalence with socio-economic classes. This was due tolow awareness in patients coming from lower socio-economic category. Also, these patients lived in overcrowded condition with poor environmental sanitation, which further contributes to more prevalence. Study suggests that some health education should also be given along with medical treatment to reduce the disease burden.

\section{Funding: Nil, Conflict of interest: None Permission of IRB: Yes}

\section{Reference}

1. Chiriac A, Foia L, Pinteala T, Chiriac AE. Acne Inversa (Hurley Clinical Stage II): Case report. Our Dermatol Online. 2011;2:216-7.

2. Inanir I, Sahin MT, Gündüz K, et al. Prevalence of skin conditions in primary school children in Turkey: differences based on socioeconomic factors. Pediatr Dermatol. 2002 Jul-Aug;19(4):307-11.
3. Andersen LK, Davis MD. Prevalence of Skin and Skin-Related Diseases in the Rochester Epidemiology Project and a Comparison with Other Published Prevalence Studies. Dermatology. 2016; 232(3):344-52. doi: 10.1159/000444580. Epub 2016 Mar 25.

4. Hay R, Bendeck SE, Chen S, Estrada R, Haddix A, McLeod T, Mahé A.. skin disease, 2nd edition ed. New York: Oxford University Press; 2006.

5. Das KK. Pattern of dermatological diseases in Gauhati Medical College and Hospital Guwahati. Indian J Dermatol VenereolLeprol. 2003 Jan-Feb;69(1):16-8.

6. Baur B, Sarkar J, Manna N, Bandyopadhyay L. The pattern of dermatological disorders among patients attending the skin OPD of a tertiary care hospital in Kolkata, India. Journal of Dental and Medical Sciences. 2013 Jan;3:1-6.

7. Rao GS, Kumar SS, Sandhya. Pattern of skin diseases in an Indian village. Indian J Med Sci. 2003 Mar;57 (3): 108-10.

8. Zamanian A, Mahjub H. Prevalence of skin diseases in Hamedan, Iran in 2002. Indian Journal of Dermatology. 2005 Oct 1;50(4):208.

9. Atraide DD, Akpa MR, George IO. The pattern of skin disorders in a Nigerian tertiary hospital. Journal of Public health and epidemiology.2011Apr30;3(4):177-81

10. Devi TB, Zamzachin G. Pattern of skin diseases in Imphal. Indian journal of Dermatology. 2006 Apr 1;51 (2): 149 .

11. Agarwal A. Social classification: the need to update in the present scenario. Indian J Community Med. 2008 Jan; 33 (1):50-1. doi: 10.4103/0970-0218.39245.

12. Symvoulakis EK, Krasagakis K, Komninos ID, et al. Primary care and pattern of skin diseases in a Mediterranean island. BMC Fam Pract. 2006 Jan 31; 7:6.DOI:10.1186/1471-2296-7-6

13. Dalgard F, Holm JØ, Svensson A, et al. Self reported skin morbidity and ethnicity: a populationbased study in a Western community. BMC Dermatol. 2007 Jun 29;7:4.DOI:10.1186/1471-5945-7-4

14. Das S, Chatterjee T. Pattern of skin diseases in a peripheral hospital's skin OPD: A study of 2550 patients. Indian Journal of Dermatology.2007Apr 1;52 (2):93 


\section{Original Research Article}

15. Manjula VD, Sreekiran S, Saril PS, et al. A study of psoriasis and quality of life in a tertiary care teaching hospital of kottayam, kerala. Indian J Dermatol. 2011 Jul; 56 (4) : 403-6. doi: 10.4103/ 0019-5154. 84767.

16. Fernandez J, Blanca M, Soriano V, Sanchez J, Juarez C. Epidemiological study of the prevalence of allergic reactions to Hymenoptera in a rural population in the Mediterranean area. Clinical and experimental allergy: journal of the British Society for Allergy and Clinical Immunology. 1999 Aug;29(8):1069-74.

17. Yasmeen N, Khan MR. Spectrum of common childhood skin diseases: a single centre experience. J Pak Med Assoc. 2005 Feb;55(2):60-3.
18. Asokan N, Prathap P, Ajithkumar K, Ambooken B, Binesh VG, George S. Pattern of skin diseases among patients attending a tertiary care teaching hospital in Kerala. Indian Journal of Dermatology, Venereology, and Leprology. 2009 Sep 1;75(5):517.

19. Dalgard F, Svensson A, Holm JØ, et al. Selfreported skin morbidity in Oslo. Associations with sociodemographic factors among adults in a crosssectional study. Br J Dermatol. 2004 Aug;151(2):452-7. DOI:10.1111/j.1365-2133.2004.06058.x

20. Hassan I, Anwar P, Bilquis S, Nabi S, Rasool F, Munshi I. Comparison of dermatoses seen in community health camps and a tertiary care centre in Kashmir. Indian Journal of Dermatology, Venereology, and Leprology. 2014 May 1;80(3):214.

\section{How to cite this article?}

Sharma P, Shah A, Lachhiramani R, Jagati A. Spectrum of dermatological manifestation in all female attending tertiary health care in a developing country. Int J Med Res Rev 2018; 6(08): 420-426. doi:10.17511/ijmrr.2018.i08.05. 